\title{
Modelagem da Lagoa da Pampulha: uma ferramenta para avaliar o impacto da bacia hidrográfica na dinâmica do fitoplâncton
}

\author{
Modelling Lake Pampulha: a tool for assessing \\ the catchment area impacts on the phytoplankton dynamics
}

\begin{abstract}
Talita Fernanda das Graças Silva', Brigitte Vinçon-Leite ${ }^{2}$, Alessandra Giani³ Cleber Cunha Figueredo ${ }^{3}$, Guido Petrucci², Bruno Lemaire ${ }^{4}$, Eduardo Von Sperling ${ }^{5}$,
\end{abstract} Bruno Tassin ${ }^{2}$, Martin Seidl ${ }^{2}$, Viet Tran Khac', Priscila Siqueira Viana ${ }^{3}$, Valquíria Flávia Lima Viana ${ }^{3}$, Rodrigo Argolo Toscano', Brenner Henrique Maia Rodrigues', Nilo de Oliveira Nascimento'

口-

\begin{abstract}
RESUMO
No processo de urbanização, o aumento na proporção de superfícies impermeabilizadas e as mudanças no uso do solo são responsáveis por maiores volumes e velocidades do escoamento superficial, refletindo em uma maior capacidade de arraste e em um maior aporte de nutrientes nos corpos dágua receptores. O objetivo deste trabalho foi implementar uma ferramenta matemática capaz de reproduzir o impacto de mudanças na bacia hidrográfica sobre a dinâmica do fitoplâncton em um lago urbano. Neste artigo são apresentados o desenvolvimento e os resultados de um modelo integrado constituído de um modelo hidrológico, para simular vazões escoadas em uma bacia hidrográfica, e de um modelo hidrodinâmico e ecológico, para simular a biomassa fitoplanctônica em um corpo d'água urbano. A Lagoa da Pampulha (Belo Horizonte, Minas Gerais), escolhida como estudo de caso, foi intensamente monitorada, assim como sua bacia de drenagem, entre outubro de 2011 e junho de 2013. Os dados obtidos foram utilizados para calibrar e validar ambos os modelos. Os resultados obtidos com o modelo hidrológico mostraram-se coerentes com as medidas realizadas em campo (o coeficiente de Nash variou entre 0,70 e 0,88). O modelo da lagoa representou corretamente a evolução da comunidade fitoplanctônica (erro médio absoluto normalizado: 0,25-0,42 e o coeficiente de Pearson: 0,82-0,89; $\mathrm{p}<0,0001$ ). O monitoramento e a modelagem da lagoa mostraram que a proliferação de cianobactérias é bastante perturbada pelas desestratificações térmicas que ocorrem na lagoa em virtude de eventos meteorológicos. A ferramenta de simulação desenvolvida possui potencial para avaliar diferentes cenários de mudança das condições climáticas e das características da bacia, podendo auxiliar na gestão dos corpos d'água situados em meio urbano.
\end{abstract}

Palavras-chave: modelagem de lagos; modelagem hidrológica; lagos urbanos.

\begin{abstract}
In urban areas the increasing imperviousness is responsible for rising runoff volume and speed, leading to a greater capacity to load nutrients and pollutants into reservoirs. In order to study the impacts of catchment changes on the phytoplankton dynamics in urban lakes, a modelling approach in which a hydrological model is connected to an ecological lake model is proposed for Lake Pampulha (Brazil). In this paper we present the methodology used to link both models. Lake Pampulha and its catchment area were intensively monitored between October 2011 and June 2013 in order to provide data for the calibration and validation of both models. The results of the hydrologic model showed good agreement with the in situ measurements, and the Nash coefficient ranged from 0.70 to 0.88. The lake ecological model have successfully represented the cyanobacteria dynamics (normalized mean average error: 0.25-0.42, Pearson coefficient: 0.82-0.89, p<0.0001). Monitoring and modelling showed that cyanobacteria blooms are quite disturbed by water column mixing caused by rain events. The mathematical tool developed here can be used to assess different scenarios of climate changes or catchment area changes and can be very helpful for the management of urban water resources.
\end{abstract}

Keywords: lake modelling; hydrological modelling; urban lakes.

'Departamento de Engenharia Hidráulica e Recursos Hídricos da Escola de Engenharia da Universidade Federal de Minas Gerais (UFMG) - Belo Horizonte (MG), Brasil. 2Ecole des Ponts Paris Tech, Université Paris-Est - Champs-sur-Marne, França.

3Laboratório de Ficologia do Departamento de Botânica do Instituto de Ciências Biológicas da UFMG - Belo Horizonte (MG), Brasil.

${ }^{4}$ Ecole des Ponts Paris Tech, Agro Paris Tech, Université Paris-Est - Paris, França.

${ }^{5}$ Departamento de Engenharia Sanitária e Ambiental da UFMG - Belo Horizonte (MG), Brasil.

Endereço para correspondência: Talita Fernanda das Graças Silva - Avenida Antônio Carlos, 6627, Escola de Engenharia, Bloco I, sala 4607, Campus Pampulha - Pampulha 31270-901 - Belo Horizonte (MG), Brasil - E-mail: talita.silva@ehr.ufmg.br

Recebido: 28/10/13 - Aceito: 29/04/15 - Reg. ABES: 125962 


\section{INTRODUÇÃO}

Nas últimas décadas, os ecossistemas lênticos situados em meio urbano têm sido seriamente afetados pelas atividades antrópicas desenvolvidas em suas bacias de drenagem, principalmente devido ao lançamento de rejeitos industriais, esgotos domésticos, drenagem pluvial, aporte de resíduos sólidos, etc. Em razão dessa pressão antrópica, vários corpos d'água em todo o mundo se encontram eutrofizados e com qualidade da água comprometida (COOKE et al., 2005). O processo de urbanização caracterizado pelo aumento na proporção de áreas impermeáveis, mudanças no uso do solo e crescimento populacional sem infraestrutura sanitária adequada acarreta um aumento no volume e na velocidade do escoamento superficial, o que se traduz em cargas de poluição difusa mais expressivas lançadas nos corpos d'água receptores (ALBERTI et al., 2000; VIEIRA et al., 2009). Dentre os diversos poluentes presentes no escoamento superficial de uma bacia hidrográfica urbana, os nutrientes nitrogênio e fósforo são os principais responsáveis por favorecer a proliferação fitoplanctônica nos lagos e reservatórios (SMITH, 2003).

A biomassa fitoplanctônica é um dos parâmetros utilizados para avaliar a qualidade da água em lagos e reservatórios, em razão de sua relevância para a biodiversidade em tais ecossistemas (REYNOLDS, 2006). Dentre as espécies fitoplanctônicas, as cianobactérias merecem atenção especial por parte dos pesquisadores, gestores e usuários dos corpos d'água devido ao seu potencial de produção de substâncias tóxicas ao homem e aos animais expostos à água contaminada. Esses microrganismos podem se desenvolver de forma extensa quando as condições ambientais são favoráveis, afetando os usos da água para abastecimento doméstico, a pesca, a recreação de contato primário e a prática de esportes náuticos. A produção excessiva de cianobactérias também diminui a biodiversidade nos meios lênticos, afetando seu funcionamento ecológico (AFSSET, 2006).

A complexidade dos fenômenos envolvidos na formação do escoamento superficial em meio urbano e no funcionamento de um ecossistema lêntico, cada um ocorrendo em escalas temporais características, faz da modelagem matemática uma ferramenta apropriada para se estudar a relação entre a quantidade e a qualidade das águas escoadas na bacia durante um evento chuvoso e a biomassa fitoplanctônica produzida nesse lago. De fato, modelos são concebidos para representar um sistema por meio de uma linguagem de fácil acesso, com o objetivo de entendê-lo e buscar suas respostas para diferentes entradas (TUCCI, 2005).

A integração entre um modelo hidrológico e o modelo ecológico de um lago ocorre por meio da utilização do escoamento superficial gerado pelo primeiro modelo como dado de entrada para o segundo modelo. Procedendo dessa forma é possível aplicar diferentes cenários de mudança da bacia hidrográfica e simular as respectivas respostas do ecossistema aquático. A intensificação do processo de urbanização, as mudanças climáticas e a crescente preocupação com a qualidade dos recursos hídricos são alguns dos cenários que podem ser explorados por meio da modelagem integrada. Xu, Godrej e Grizzard (2007) e Norton et al. (2012) destacam que a modelagem integrada é uma abordagem de maior receptividade por parte dos gestores e do público em geral, uma vez que ela pode ser mais facilmente percebida como uma representação de sistemas naturais e suas interconexões.

Diversos estudos integraram dois ou mais modelos matemáticos para avaliar como mudanças na política de planejamento urbano, mudanças climáticas, a intensificação do processo de urbanização e mudanças no uso do solo podem afetar os ambientes lacustres. Wu, Yu e Zou (2006) utilizaram em conjunto o modelo hidrológico HSPF e o modelo de simulação da qualidade de reservatórios CE-QUAL-W2 para definir as técnicas compensatórias mais adequadas para reduzir as cargas de fósforo e nitrogênio afluentes ao reservatório Swift Creek (EUA). Os efeitos de mudanças climáticas sobre o ciclo hidrológico e sobre a dinâmica físico-química e biológica de ecossistemas lênticos foram estimados por Taner, Carleton e Wellman (2011), que aplicaram uma modelagem integrada ao Lago Onondaga (EUA). As mudanças nos padrões de temperatura do ar e intensidade das chuvas foram baseadas em cenários do Intergovernmental Panel on Climate Change (IPCC) e simuladas pelos modelos HSPF (hidrológico), UFILS4 (hidrodinâmico) e AQUATOX (ecológico). Em relação aos impactos provocados pela urbanização, Fragoso Junior (2007) e Nobre et al. (2010) simularam cenários envolvendo melhorias no saneamento da bacia hidrográfica e estimaram as mudanças na contribuição de nutrientes e em matéria orgânica, respectivamente no estuário do Rio Bacanga (São Luís, Maranhão) e na Baía de Xiangshan Gang (China). O primeiro autor denominou sua abordagem como modelagem integrada e no segundo trabalho definiu-se a metodologia como modelagem de ecossistemas em múltiplas camadas.

Quanto às mudanças no uso e na ocupação do solo na bacia hidrográfica e suas respectivas consequências sobre a dinâmica do fitoplâncton no corpo d'água, poucos estudos abordaram a questão de forma integrada, principalmente em bacias hidrográficas urbanas. Como exemplos em que a modelagem do escoamento superficial foi integrada à modelagem de um sistema lacustre, pode-se citar o trabalho de Xu, Godrej e Grizzard (2007), somente para volumes de água escoados (abordagem quantitativa), e de Norton et al. (2012), para a dinâmica físico-química e do fitoplâncton (abordagem quali-quantitativa), ambos aplicados em regiões não urbanizadas.

O objetivo deste trabalho foi apresentar uma ferramenta matemática que: seja capaz de reproduzir a dinâmica do fitoplâncton em um lago urbano e possa ser utilizada para avaliar como mudanças na bacia hidrográfica podem afetar o comportamento de ambientes lênticos urbanos, principalmente no que se refere ao fitoplâncton. Para isso, propôs-se a utilização acoplada da modelagem matemática do escoamento superficial urbano e da modelagem da dinâmica do fitoplâncton. As etapas de integração de ambos os modelos descritas neste trabalho consistem em: 
1. calibrar e validar o modelo hidrológico por meio de dados obtidos em campo,

2. introduzir as vazões produzidas nesse modelo como dado de entrada no modelo da lagoa,

3. calibrar e validar o modelo da lagoa com dados obtidos por meio de monitoramento.

\section{METODOLOGIA}

\section{Área de estudo}

A Lagoa da Pampulha (Figura 1) é uma represa hipereutrófica de pequenas dimensões situada no município de Belo Horizonte (MG) (coordenadas WGS84 1951'09” S; 4358'42”O). Trata-se de um corpo d'água inserido em uma bacia hidrográfica urbanizada onde a ocupação desordenada e a carência de infraestrutura de saneamento e de controle de erosão levaram à perda de cerca de $50 \%$ de seu volume original (RESCK et al., 2007), assim como causaram uma intensa degradação da qualidade de suas águas. Episódios de proliferações de cianobactérias, inclusive de espécies potencialmente tóxicas, foram frequentes ao longo de todo o ano de 2010 (LOPES, 2013). Algumas características morfométricas da lagoa, assim como parâmetros físicos, químicos e biológicos referentes à qualidade da água, estão listadas na Tabela 1 .

O clima da região é classificado como tropical de altitude, com duas estações bem definidas ao longo do ano: a estação chuvosa, entre outubro e março, e a estação seca, entre abril e setembro. Durante a estação chuvosa, ocorre cerca de $90 \%$ da precipitação média anual, cujo valor é de $1.500 \mathrm{~mm}_{\text {. }} \mathrm{no}^{-1}$ (NASCIMENTO et al., 2006). A temperatura do ar apresenta pequena amplitude ao longo do ano, sendo a mínima média mensal de $13,1^{\circ} \mathrm{C}$, registrada em julho, e a máxima média mensal de 28,8 $\mathrm{C}$, em fevereiro (CPRM, 2001, série histórica entre 1961-1990, estação INMET Belo Horizonte).

A Lagoa da Pampulha possui oito tributários diretos (Figura 1), sendo os Córregos Ressaca e Sarandi os mais relevantes em termos de área de drenagem e de carga poluidora, respondendo por cerca de $70 \%$ do volume afluente ao lago (TÔRRES; RESCK; PINTO-COELHO, 2007). Apesar da degradação da qualidade de suas águas, a represa é um dos cartões-postais da cidade e seu entorno é frequentemente utilizado para manifestações festivas, grandes eventos esportivos e prática de esportes. Além disso, a Lagoa da Pampulha também desempenha a função de amortecimento de cheias, evitando enchentes a jusante de seu exutório.

\section{Monitoramento e coleta de dados}

\section{Monitoramento da bacia hidrográfica}

Atualmente o monitoramento da bacia hidrográfica da Lagoa da Pampulha restringe-se às bacias dos Córregos Ressaca e Sarandi e é realizado em parceria com a Prefeitura Municipal de Belo Horizonte (PBH). A rede de monitoramento é composta por quatro estações fluviométricas automáticas para medição da precipitação e do nível d'água nos córregos. Em outros locais, dentro ou próximos da bacia hidrográfica, operam três estações pluviométricas e uma estação meteorológica (Figura 1). Todos os dados são obtidos a cada 10 minutos e passaram a ser disponibilizados em tempo real a partir de outubro de 2011.

Para obter as vazões escoadas nos córregos a partir dos dados de nível d’água, mediu-se a velocidade do escoamento em tempo seco com o auxílio do molinete FlowProbe 1.0 (Global Water, EUA). Em razão de velocidades elevadas de escoamento nos canais urbanos revestidos em concreto e de riscos associados a corpos flutuantes, a medição com molinete não é possível para vazões elevadas. Assim, em tempo chuvoso, flutuadores foram utilizados e um fator de correção ajustou as velocidades superficiais à velocidade média na seção (ROCHE, 1963). A partir das velocidades obtidas, estimou-se o coeficiente de rugosidade dos canais (n) por meio da equação de Manning, admitindo-se escoamento em regime permanente uniforme. Para levar em consideração a variabilidade do coeficiente de rugosidade com o nível d’água no canal, utilizou-se a equação proposta por Bertrand-Krajewski et al. (1997).

O monitoramento da qualidade da água dos Córregos Ressaca e Sarandi foi realizado entre fevereiro de 2012 e janeiro de 2013. Nos seis primeiros meses de monitoramento, amostras pontuais foram coletadas com frequência bimestral logo após a confluência dos córregos (na Figura 1, ponto "Estação qualidade"). A partir de agosto de 2012, coletas mensais passaram a ser realizadas no mesmo local. As seguintes variáveis foram analisadas: turbidez, $\mathrm{pH}$, condutividade elétrica, sólidos suspensos, nitrogênio amoniacal $\left(\mathrm{NH}_{4}^{+}\right)$, nitrogênio total Kjeldahl (NTK), nitrito $\left(\mathrm{NO}_{2}^{-}\right)$, nitrato $\left(\mathrm{NO}_{3}^{-}\right)$, fósforo total (P-total) e fosfato $\left(\mathrm{PO}_{4}^{3-}\right)$. Medidas de temperatura da água foram realizadas entre fevereiro e abril de 2013 utilizando-se um sensor de temperatura automático (Global Water, EUA) cuja frequência de obtenção de dados foi de 5 minutos. A partir dos dados registrados, calculou-se a temperatura média diária e procedeu-se a uma regressão linear simples com as médias diárias de temperatura do ar (dados fornecidos pelo Instituto Nacional de Meteorologia - INMET, como descrito no item "Monitoramento da lagoa"). A equação obtida $\left(\mathrm{r}^{2}=0,65 ; \mathrm{p}<0,00001\right)$ foi utilizada para estimar a temperatura média diária da água afluente à lagoa a partir da temperatura média diária do ar.

Os dados referentes ao uso e ocupação do solo e às taxas de impermeabilização na bacia hidrográfica foram obtidos por meio de imagens de satélite de alta resolução (data das imagens: 12 de fevereiro de 2013), utilizando-se o software Google Earth (versão livre 7.1.1.1888). A partir de interpretação dessas imagens, foram vetorizadas as classes de uso do solo existentes na região, dados posteriormente tratados e analisados utilizando-se o software ArcGis (versão10.1) para determinação das áreas associadas às classes propostas. 


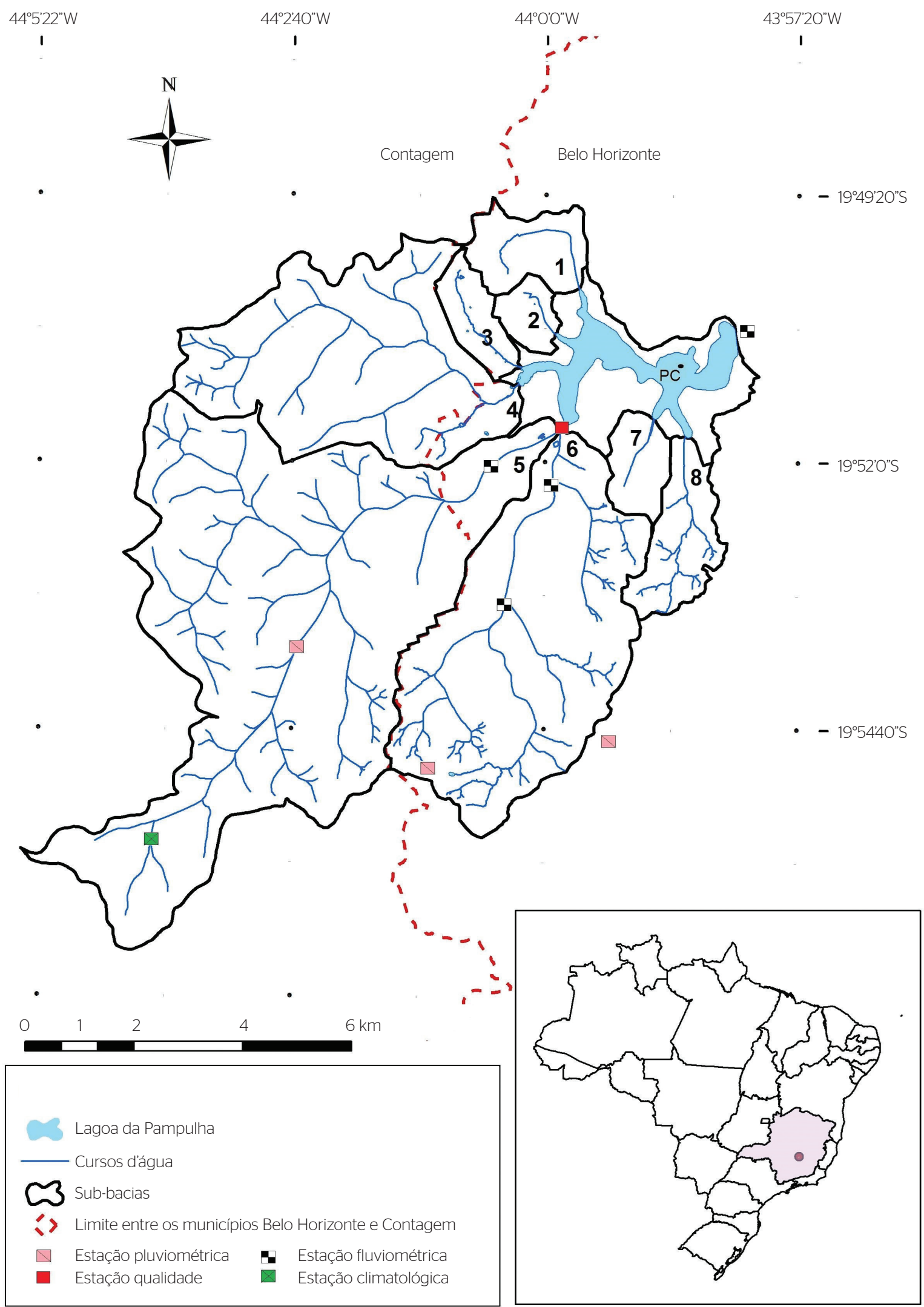

PC: ponto central de monitoramento na Lagoa da Pampulha

Figura 1 - Tributários diretos da Lagoa da Pampulha: (1) Olhos d’água; (2) AABB; (3) Braúnas; (4) Água Funda; (5) Sarandi; (6) Ressaca; (7) Tijuco; (8) Mergulhão. 


\section{Monitoramento da lagoa}

O monitoramento da lagoa foi realizado entre outubro de 2011 e junho de 2013 e consistiu em campanhas mensais para coleta de amostras e medição de parâmetros físico-químicos em uma região central da lagoa (ponto PC na Figura 1), cuja profundidade máxima é de 10,0 m. Durante o primeiro ano de monitoramento, dois outros locais, um a montante e o outro a jusante desse ponto central, também foram acompanhados para avaliar a heterogeneidade espacial da lagoa. Os parâmetros medidos in situ foram: temperatura, oxigênio dissolvido, $\mathrm{pH}$ e condutividade elétrica, obtidos a cada $0,50 \mathrm{~m}$ de profundidade com a sonda multiparâmetros YSI 556 (EUA), e transparência da água, medida com um disco de Secchi. Amostras coletadas a 0,50 m de profundidade foram analisadas em laboratório para determinação das concentrações de $\mathrm{NO}_{3}, \mathrm{NO}_{2}, \mathrm{NH}_{4}^{+}, \mathrm{PO}_{4}^{3-}$ e P-total segundo a American Public Health Association (APHA, 1998). A análise de clorofila-a foi realizada de acordo com Nusch (1980); a identificação e contagem dos organismos fitoplanctônicos seguiu o método proposto por Utermöhl (1958). Entre dezembro de 2012 e junho de 2013, amostras também foram coletadas entre 1,50 e $8,0 \mathrm{~m}$ de profundidade.

As condições climáticas nas proximidades da lagoa foram registradas pela estação meteorológica automática A521 - Belo Horizonte (Pampulha) do INMET. Informações referentes à batimetria da lagoa foram obtidas no estudo realizado por Resck et al. (2007).

\section{Modelagem hidrológica da bacia hidrográfica}

\section{Modelo hidrológico adotado}

Para a simulação dos volumes escoados nas sub-bacias dos Córregos Ressaca e Sarandi, adotou-se o modelo determinístico Storm Water Management Model - SWMM (ROSSMAN, 2010). Trata-se de um modelo de simulação dinâmica da relação chuva-vazão em bacias

Tabela 1 - Características da Lagoa da Pampulha.

\begin{tabular}{|c|c|}
\hline Altitude & $801 \mathrm{~m}$ \\
\hline Profundida de médiaa & $5,1 \mathrm{~m}$ \\
\hline Profundida de máximaa & $16,2 \mathrm{~m}$ \\
\hline Área $^{a}$ & 197 ha \\
\hline Volume $^{\text {a }}$ & $9,9 \times 10^{6} \mathrm{~m}^{3}$ \\
\hline$P_{\text {total }}^{b}$ & 58-925 (207) $\mu \mathrm{g} P \mathrm{~L}^{-1}$ \\
\hline $\mathrm{PO}_{4}^{-3 b}$ & $1,7-113,1(22,1) \mu \mathrm{g} P \mathrm{~L}^{-1}$ \\
\hline $\mathrm{NH}_{4}^{+\mathrm{b}}$ & $1,4-14,8(5,71) \mathrm{mg} \mathrm{N} \mathrm{L-1}^{-1}$ \\
\hline $\mathrm{NO}_{3}^{-b}$ & $3,1-460(82,9) \mu g N^{-1}$ \\
\hline Clorofila-ab & $19,5-322,0(113,0) \mu g L^{-1}$ \\
\hline
\end{tabular}

aResck et al. (2007)

'Monitoramento realizado entre dezembro de 2011 e maio de 2013. Valor mínimovalor máximo (valor médio) durante o período de monitoramento. Informações

detalhadas sobre o monitoramento da lagoa são apresentadas no item

"Monitoramento da Lagoa". hidrográficas urbanas e da propagação de cheias em rios, canais e lagos. No modelo SWMM, três elementos são utilizados para representar a bacia hidrográfica: as sub-bacias nas quais ocorrem a precipitação e a formação do escoamento superficial; os nós, que são pontos de entrada do escoamento superficial na rede de drenagem; essa, por sua vez, é representada pelo terceiro elemento do modelo, os condutos. O cálculo da precipitação efetiva pode ser baseado nos modelos de Green-Ampt, Horton ou Curve Number (TUCCI, 2012). O escoamento sobre a superfície da bacia é simulado por meio do modelo de reservatório não linear. O escoamento nos canais é computado em regime não permanente com o auxílio das equações de Saint-Venant. Mais detalhes sobre o modelo SWMM podem ser encontrados em Rossman (2010).

\section{Configuração, calibração e validação do modelo hidrológico}

A modelagem hidrológica foi realizada para os córregos cujos dados de vazão estavam disponíveis. As áreas de drenagem dos Córregos Ressaca e Sarandi foram divididas, respectivamente, em 47 e 10 sub-bacias de acordo com as características topográficas, os dados cadastrais da rede de águas pluviais e a locação do sistema de drenagem (BONNARY, 2011). A precipitação efetiva foi calculada pelo método Curve Number (CN), sendo que a cada sub-bacia atribuiu-se um CN de acordo com o uso e ocupação do solo verificado nas imagens de satélite e informações disponíveis sobre os tipos de solo na bacia (CPRM, 2001). Para a propagação de cheias nos canais, adotou-se o modelo da onda cinemática. O método dos polígonos de Thiessen foi utilizado para distribuir espacialmente sobre as sub-bacias a precipitação registrada pelas estações pluviométricas. Adotou-se 10 minutos como intervalo de tempo de cálculo do modelo.

Certos parâmetros do modelo hidrológico apresentam elevado grau de dificuldade e de incerteza em sua determinação, por exemplo: o coeficiente de rugosidade dos condutos $\left(\mathrm{n}_{\text {cond }}\right)$, o coeficiente de rugosidade de áreas permeáveis $\left(\mathrm{n}_{\text {perm }}\right)$ e impermeáveis $\left(\mathrm{n}_{\mathrm{imp}}\right)$, o coeficiente de armazenamento em depressões em área permeáveis $\left(\mathrm{s}_{\text {perm }}\right)$ e impermeáveis $\left(\mathrm{s}_{\mathrm{imp}}\right)$, o tempo necessário para que toda água evapore de uma amostra de solo completamente saturada $\left(\mathrm{d}_{\text {time }}\right)$ e a largura característica do escoamento superficial em cada sub-bacia (w). Para os parâmetros relacionados acima, procedeu-se à calibração do modelo com os dados disponíveis entre 29 de janeiro de 2012 a 30 de junho de 2012 para o Córrego Ressaca e entre 18 de novembro de 2011 a 30 de junho de 2012 para o Córrego Sarandi. Para isso, utilizou-se um método automático baseado em algoritmos genéticos, tendo o critério de Nash-Sutcliffe (NASH \& SUTCLIFFE, 1970) como função objetivo (PETRUCCI et al., 2013). Os valores adotados para cada parâmetro são apresentados no Anexo 1. O modelo calibrado foi validado utilizando-se uma série independente de dados obtidos entre 1 de julho de 2012 
a 4 de junho de 2013 no Córrego Ressaca e entre 1 de julho de 2012 e 15 de fevereiro de 2013 no Córrego Sarandi.

\section{Modelagem do fitoplâncton da lagoa}

\section{Modelo adotado para a lagoa}

Os modelos de ecossistemas lênticos são frequentemente constituídos de um módulo hidrodinâmico e de um módulo ecológico: o primeiro descreve os processos físicos de transporte e turbulência na coluna d'água, enquanto o segundo representa os principais processos químicos e biológicos que afetam a comunidade fitoplanctônica e os níveis tróficos superiores. Neste estudo, o modelo determinístico DYRESMCAEDYM (DYCD) foi adotado para simular a temperatura da água e a biomassa fitoplanctônica na Lagoa da Pampulha. O DYRESM DYnamic REServoir Simulation Model - é um modelo hidrodinâmico unidimensional que simula a distribuição vertical da temperatura, salinidade e densidade da água em lagos e reservatórios (HAMILTON \& SCHLADOW, 1997). O modelo CAEDYM - Computational Aquatic Ecosystem Dynamics Model — consiste em uma série de equações diferenciais de conservação das massas das diferentes variáveis que o compõem. O DYCD pode ser empregado em estudos biológicos e/ou químicos sobre o ciclo dos nutrientes, a sucessão algal, os metais pesados, a dinâmica de patógenos na água, entre outros (HIPSEY et al., 2006).

Para o fitoplâncton, os processos representados no modelo compreendem

1. o crescimento limitado pelas condições de temperatura, luminosidade e disponibilidade de nutrientes e

2. as perdas relacionadas à mortalidade biológica, à excreção e à respiração.

Os dados de entrada necessários ao DYCD são: batimetria da lagoa; volumes diários afluentes à lagoa e suas respectivas temperaturas e concentrações em nutrientes; volume diário de água na saída da lagoa; dados meteorológicos (velocidade do vento, temperatura do ar, nebulosidade, radiação solar, precipitação e pressão de vapor); condições iniciais para a temperatura da água, biomassa do fitoplâncton, concentração dos nutrientes e do oxigênio dissolvido. Maiores informações sobre DYCD podem ser encontradas em Gal et al. (2009) e Hamilton e Schladow (1997).

\section{Configuração, calibração e validação do modelo da lagoa}

O modelo DYCD foi configurado para simular a temperatura da água, as concentrações de nitrogênio e fósforo e a biomassa total do fitoplâncton, representada pela concentração equivalente em clorofila-a (chl-a). A análise taxonômica das amostras coletadas na lagoa mostrou que a biomassa de cianobactérias respondeu por, pelo menos, $80 \%$ da comunidade fitoplanctônica em 19 das 22 amostras analisadas. As espécies de cianobactéria dominantes foram Planktothrix isothrix (Skuja) Komárek \& Komárková e Cylindrospermosisraciborskii (Woloszyńska) Seenayya \& SubbaRaju. Nas três amostras em que não se verificou dominância de cianobactérias, espécies dos filos Chlorophyta, Cryptophyta e Euglenophyta foram detectadas em maior quantidade (dados não publicados). Tendo em vista a significativa participação das cianobactérias na comunidade fitoplanctônica da Lagoa da Pampulha, optou-se por modelá-las explicitamente, e os demais filos foram agregados em um único grupo.

As vazões diárias afluentes à lagoa foram obtidas a partir da agregação das vazões simuladas pelo modelo hidrológico SWMM a cada 10 minutos (após calibração e validação do modelo). Para as concentrações em nitrato, amônio e fosfato nas vazões afluentes, optou-se por adotar valores de concentração média em tempo seco e em tempo chuvoso, obtidos a partir dos resultados das amostragens realizadas nos córregos. Em relação às variáveis meteorológicas, a nebulosidade foi determinada a partir da diferença entre a radiação solar registrada e a radiação solar teórica computada segundo método descrito por Tennessee Valley Authority (TVA, 1972).

O modelo DYCD possui um elevado número de parâmetros que pode se aproximar de uma centena para simulação de apenas um grupo fitoplanctônico e das variáveis obrigatórias. Esses parâmetros dependem de características específicas a cada ecossistema e, na maior parte das vezes, poucas informações estão disponíveis para estimá-los, sendo necessário recorrer à calibração. Para identificar os parâmetros capazes de alterar mais significativamente o modelo da Lagoa da Pampulha, procedeu-se a uma análise de sensibilidade variando-se um parâmetro por vez. Verificou-se que 18 parâmetros afetaram a capacidade do modelo em prever a biomassa fitoplanctônica em mais de $10 \%$ quando assumiam valores mínimo e máximo obtidos na literatura.

Esses 18 parâmetros foram então calibrados da seguinte forma:

1. por meio de consulta bibliográfica e dos dados obtidos no monitoramento da lagoa, determinou-se um intervalo de variação para cada parâmetro,

2. fez-se variar o valor do primeiro parâmetro dentro de seu intervalo e reteve-se o valor que resultou na melhor performance do modelo,

3. passou-se ao segundo parâmetro e assim sucessivamente até concluir um ciclo com os 18 parâmetros,

4. novos ciclos foram iniciados até que não fosse mais possível detectar mudanças significativas no desempenho do modelo.

Os parâmetros calibrados e respectivos intervalos de variação são mostrados no Anexo 2. Após a etapa de calibração entre 18 de outubro de 2011 e 18 de outubro de 2012, o modelo ajustado foi avaliado com uma série independente de dados obtidos entre 19 de outubro de 2012 e 4 de junho de 2013. 


\section{RESULTADOS}

\section{Simulação do escoamento superficial}

Os resultados das simulações hidrológicas nas bacias dos Córregos Ressaca e Sarandi são mostrados na Figura 2. Na simulação do Córrego Ressaca, obtiveram-se os valores de 0,70 e 0,72 para o coeficiente de Nash, respectivamente nas fases de calibração e validação. O modelo apresentou desempenho ainda melhor para o Córrego Sarandi, o coeficiente de Nash assumindo os valores 0,88 (calibração) e 0,78 (validação). Esses valores indicam uma boa concordância entre a simulação e as medidas. Além disso, a comparação dos hidrogramas das vazões simuladas e das vazões medidas mostra que o modelo é capaz de reproduzir muito bem os momentos de início e fim das cheias nos cursos d'água, assim como o tempo de pico. Em relação à estimação das vazões de pico, o modelo falhou em alguns eventos chuvosos, ora subestimando, ora superestimando a intensidade das vazões.

\section{Simulação da biomassa fitoplanctônica}

Os resultados do modelo para a biomassa fitoplanctônica na profundidade de 0,50 $\mathrm{m}$ foram comparados com os dados obtidos em campo (Figura 3). Nas campanhas nas quais foram recolhidas amostras em mais de uma profundidade, o perfil vertical simulado foi comparado com os dados observados (Figura 4). O coeficiente de correlação de Pearson (r) e o erro absoluto normalizado (NMAE) foram computados para avaliar o desempenho do modelo e compará-lo com outros estudos.

O modelo reproduz com boa acurácia as tendências gerais de aumento e diminuição da biomassa do fitoplâncton durante o período de simulação (Figura 3). Esse comportamento é evidenciado pelos valores significativos obtidos para o coeficiente de correlação de Pearson (0,89 e 0,82, respectivamente nas simulações de calibração e validação, com $\mathrm{p}<0,0001$ ), que indica o grau de correspondência entre as tendências sazonais do modelo e da realidade observada em campo. Os perfis verticais de chl-a obtidos em campo mostraram que

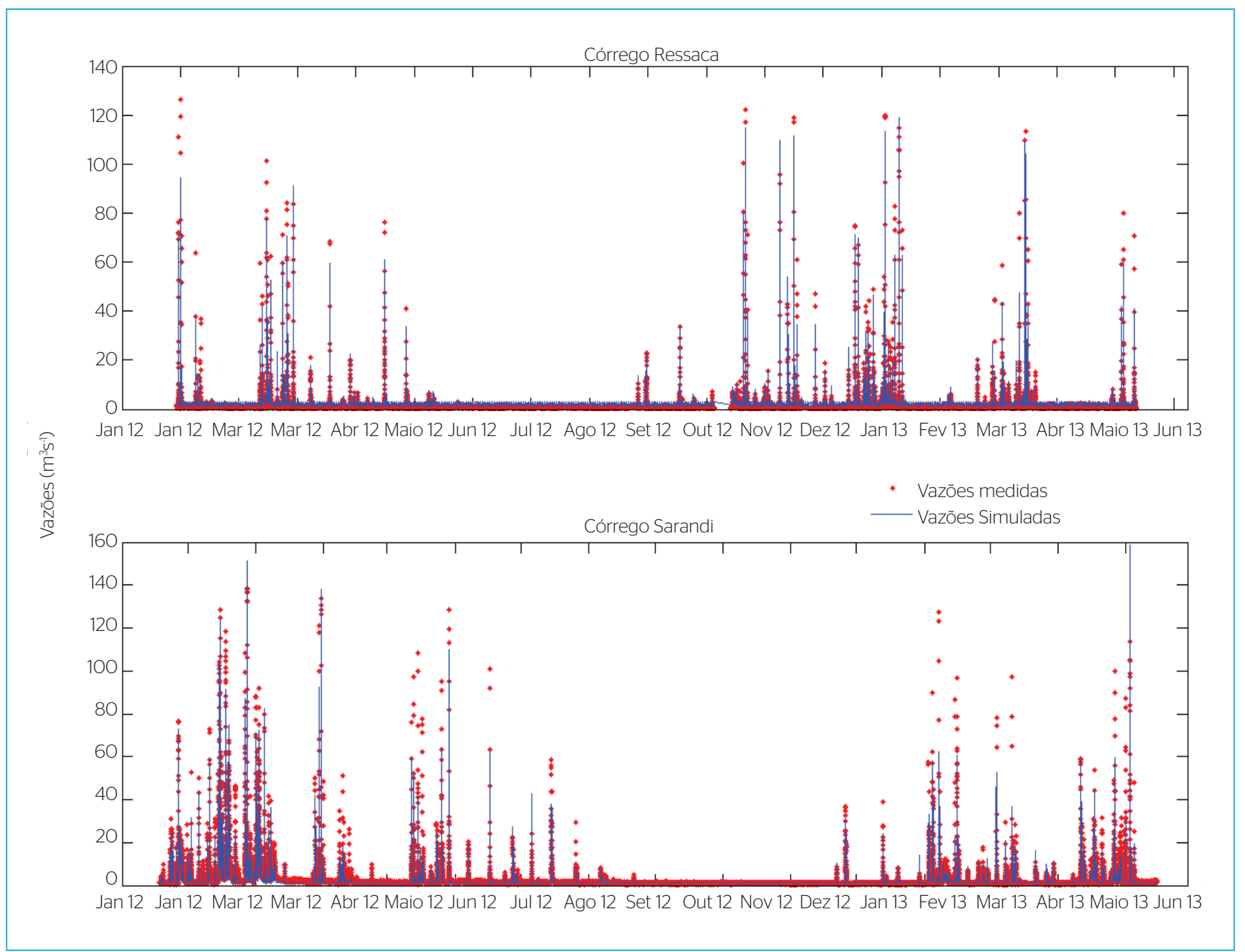

Figura 2 - Hidrograma medido e simulado pelo modelo hidrológico nos Córregos Ressaca (calibração: de 29 de janeiro de 2012 a 30 de junho de 2012 ; validação: de 1 de julho de 2012 a 4 de junho de 2013) e Sarandi (calibração: de 18 de novembro de 2011 a 30 de outubro de 2012; validação: de 1 de julho de 2012 a 15 de fevereiro de 2013), ambos afluentes da Lagoa da Pampulha (Belo Horizonte, Minas Gerais). 


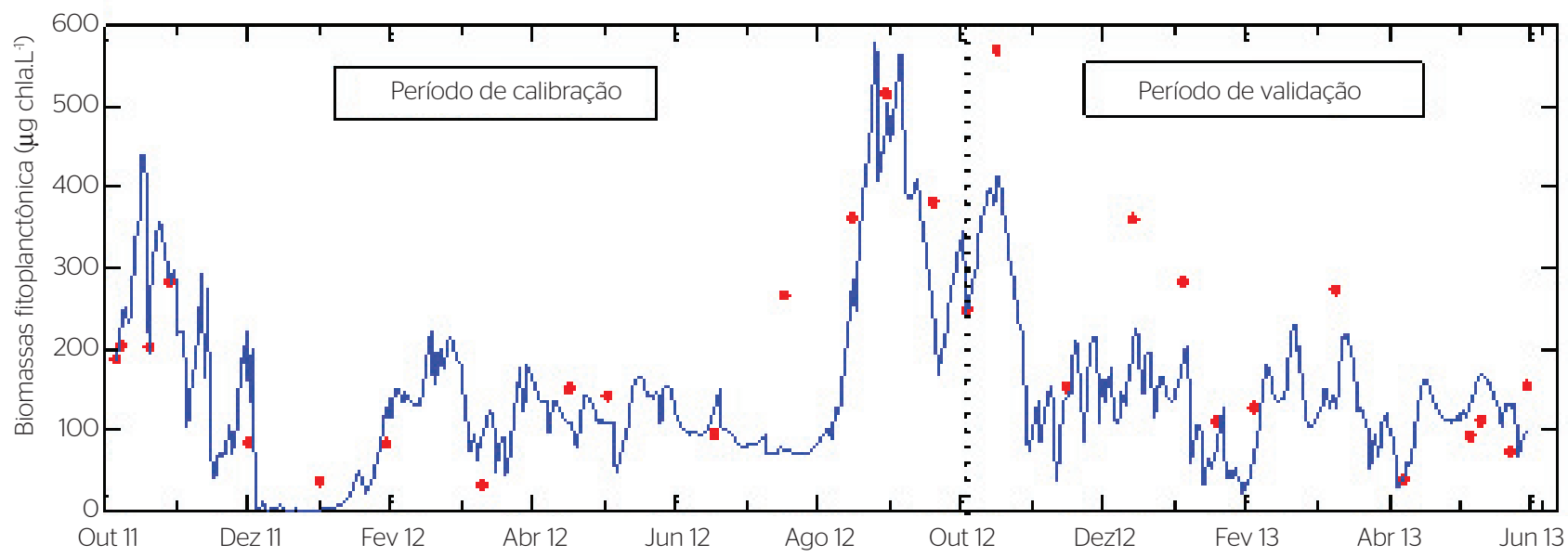

Figura 3 - Resultados do modelo (linha) e medidas em campo (pontos) para a biomassa fitoplanctônica a 0,50 m de profundidade na Lagoa da Pampulha (Belo Horizonte, Minas Gerais). A linha vertical pontilhada separa os períodos de calibração (de 18 de outubro de 2011 a 18 de outubro de 2012) e validação (de 19 de outubro de 2012 a 04 de junho de 2013) do modelo.

19-Dez-2012

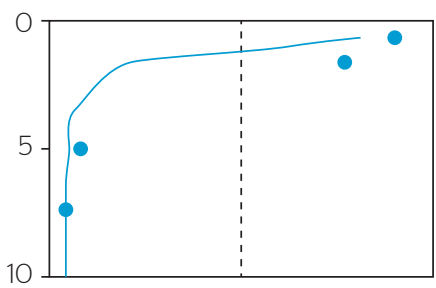

08-Fev-2013

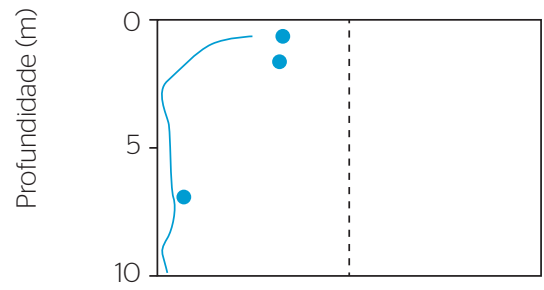

12-Abr-2013

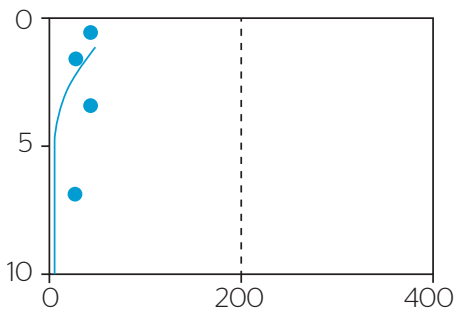

09-Jan-2013

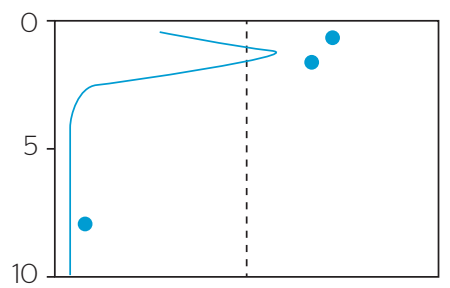

26-Fev-2013

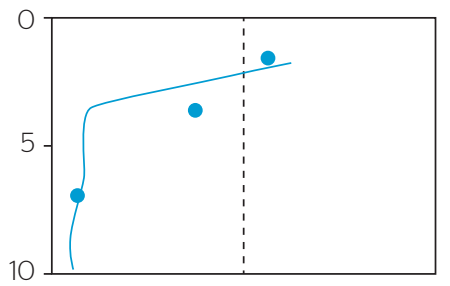

10-Maio-2013

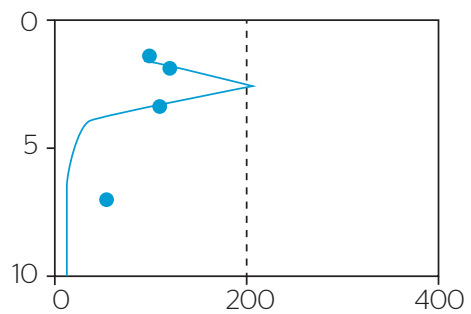

23-Jan-2013

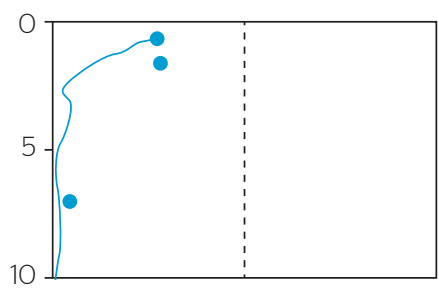

14-Mar-2013

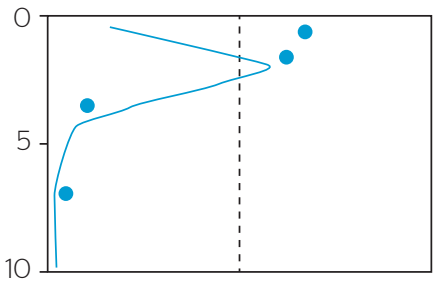

O3-Jun-2013

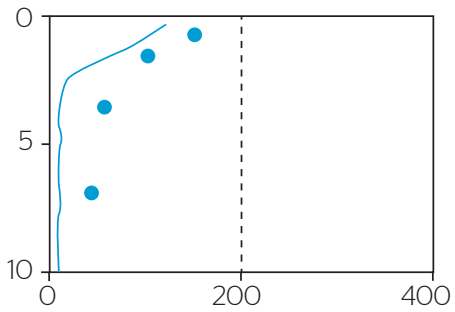

Biomassas fitoplanctônica ( $\mu \mathrm{g}$ chla..'ำ)

Figura 4 - Resultados do modelo (linha) e medidas em campo (pontos) para a biomassa fitoplanctônica na Lagoa da Pampulha (Belo Horizonte, Minas Gerais). Período de simulação - calibração (de 18 de outubro de 2011 a 18 de outubro de 2012) e validação (de 19 de outubro de 2012 a 4 de junho de 2013 ). 
o modelo também foi capaz de reproduzir a dinâmica algal em profundidades maiores do que 0,50 m (Figura 4). Em relação à magnitude da biomassa fitoplanctônica, o modelo forneceu valores bastante coerentes com os dados observados, principalmente no período de calibração, o que se reflete nos valores de $\operatorname{NMAE}(0,25$ na calibração e 0,42 na validação).

Apesar de o modelo ter subestimado a biomassa fitoplanctônica em julho, outubro e dezembro de 2012, janeiro e março de 2013, ele foi capaz de reproduzir a evolução geral dessa variável. Apenas em julho de 2012 o modelo simulou uma biomassa algal inferior ao valor observado e não capturou a tendência de crescimento apresentada pela comunidade fitoplanctônica.

\section{DISCUSSÃO}

\section{Desempenho dos modelos}

De acordo com Bennis e Crobeddu (2007), na modelagem do escoamento superficial pode-se considerar que existe um bom ajuste entre vazões observadas e simuladas quando se obtêm coeficientes de Nash superiores a 0,70 . Dessa forma, o desempenho do modelo hidrológico que simulou as vazões nos Córregos Ressaca e Sarandi pode ser considerado satisfatório (coeficiente de Nash entre 0,70 e 0,88) e compatível com resultados reportados na literatura (DOTTO et al., 2012; PETRUCCI \& BONHOMME, 2014). Em relação à utilização das vazões simuladas como dado de entrada no modelo da lagoa, a capacidade desse último em reproduzir o nível d'água pode ser considerada uma evidência de que os erros cometidos pelo modelo hidrológico não afetam muito a modelagem da biomassa fitoplanctônica. De fato, no período entre 13 de outubro de 2011 e 10 de janeiro de 2012, a PBH monitorou o nível d'água da Lagoa da Pampulha junto ao vertedouro principal da barragem. Os níveis d'água simulados pelo modelo da lagoa são similares aos valores medidos e a diferença média entre os dois durante esse período chuvoso foi de $0,04 \mathrm{~m}$ para uma profundidade total de $16 \mathrm{~m}$. Já durante a estação seca em 2012 e 2013, apesar da inexistência de registros do nível d'água, este pouco variou segundo os resultados do modelo, o que está de acordo com as expectativas para esse período.

Segundo Arhonditsis e Brett (2004), ainda não existe um índice para quantificar o desempenho de modelos aquáticos biogeoquímicos que seja aceito universalmente e que leve em consideração fatores importantes, como a duração da simulação e a complexidade do modelo (número de variáveis de estado simuladas). Esses mesmos autores analisaram os resultados de 153 modelos similares a DYCD e obtiveram valores medianos do NMAE e do coeficiente de correlação de Pearson iguais a, respectivamente, 0,44 e 0,69 para a simulação do fitoplâncton. Os resultados obtidos para a Lagoa da Pampulha tanto na fase de calibração (NMAE=0,25; r=0.89) como na etapa de validação ( $\mathrm{NMAE}=0,42 ; \mathrm{r}=0.82$ ) podem, portanto, ser considerados bastante satisfatórios.

Um dos grandes desafios em implementar modelos complexos como DYCD consiste na obtenção de dados suficientes para estabelecer as condições iniciais, as condições de contorno, calibrar e validar o modelo (ANDERSON, 2005). Por exemplo, no caso das vazões afluentes, de acordo com a disponibilidade de dados, as concentrações dos nutrientes podem ser fornecidas em intervalos de tempo diários (GAL et al., 2009), mensais (TROLLE; JØRGENSEN; JEPPESEN, 2008) ou ainda calculadas por meio de interpolações diárias a partir de observações mensais (TROLLE et al., 2011). No presente estudo, utilizaram-se concentrações médias dos nutrientes nas vazões de entrada em tempo chuvoso e em tempo seco. Para analisar a sensibilidade do modelo em relação às entradas de fosfato e verificar se a utilização de concentrações médias é uma aproximação aceitável para a Lagoa da Pampulha, variou-se em $\pm 33 \%$ as concentrações de fosfato nas vazões afluentes e verificou-se o respectivo impacto sobre o desempenho do modelo. A variação realizada correspondeu à adição/subtração nas concentrações médias do valor do desvio padrão calculado a partir dos resultados das amostragens realizadas nos córregos. O desempenho do modelo apresentou uma degradação de apenas $10 \%$ para o coeficiente de Pearson e o NMAE, indicando que a concentração média em fosfato é uma aproximação razoável que pode ser adotada nesse caso. Evidentemente, a capacidade preditiva do modelo poderia ser melhorada com uma maior disponibilidade de dados.

De fato, a produção de biomassa fitoplanctônica no modelo é limitada em função da temperatura da água e da disponibilidade de luz, nitrogênio e fósforo (HAMILTON \& SCHLADOW, 1997). Verificou-se que em todos os momentos em que o modelo subestimou significativamente a biomassa fitoplanctônica (julho, agosto, outubro e dezembro de 2012, janeiro e março de 2013), a limitação pelo fósforo $\mathrm{f}(\mathrm{P})$ atingia valores críticos da ordem de $0,1(\mathrm{f}(\mathrm{p})=1$ : ausência de limitação; $\mathrm{f}(\mathrm{P})=0$ : inibição total do crescimento). A falha do modelo nesses momentos deve-se, provavelmente, a uma insuficiência de fósforo na coluna d'água simulada, o que impediu o fitoplâncton de atingir os valores de biomassa registrados em campo. Embora a magnitude da biomassa tenha sido subestimada pelo modelo, a carência em fósforo não foi suficientemente elevada para impedir o modelo de reproduzir a tendência de crescimento algal (exceto em agosto de 2012).

\section{Análise da dinâmica fitoplanctônica na Lagoa da Pampulha}

O monitoramento da Lagoa da Pampulha e os resultados obtidos com o modelo mostraram que a comunidade fitoplanctônica pode atingir altos valores de biomassa (até $570 \mu \mathrm{g}$ chla. $\mathrm{L}^{-1}$ em outubro de 2012) e 
sua distribuição vertical é caracterizada por uma concentração nos primeiros dois metros abaixo da superfície d'água (Figura 4). Em profundidades maiores, a ausência de luz (profundidade de Secchi média no período estudado=0,37 m), em grande parte em razão do sombreamento causado pela própria biomassa algal (SCHEFFER et al., 1997), inibe o crescimento fitoplanctônico.

Em relação aos mecanismos que influenciam a dinâmica fitoplanctônica na Lagoa da Pampulha, os resultados do modelo indicaram que quando a produção de biomassa não é limitada pela baixa disponibilidade de luz (ou durante a noite ou em dias nublados), o fósforo torna-se o principal fator limitante em $70 \%$ do tempo. Esse resultado está de acordo com as análises microscópicas das amostras de fitoplâncton que constataram que apenas alguns filamentos de C. raciborskii eram dotados de heterócitos (células especializadas na fixação do nitrogênio atmosférico). A ausência de heterócitos é um indicativo de que o nitrogênio presente no meio é suficiente para o desenvolvimento dessa espécie e não é necessário fixar o nitrogênio atmosférico (PADISÁK, 1997).

Por ser um ambiente hipereutrófico situado em região tropical com temperaturas elevadas durante o ano todo, a Lagoa da Pampulha fornece condições ideais para a proliferação de cianobactérias. Em um monitoramento realizado entre 2010 e 2011 foi verificado que a dominância desse grupo fitoplanctônico perdura ao longo de todo o ano (LOPES, 2013). Os resultados obtidos com o presente estudo mostraram que durante $\mathrm{o}$ período chuvoso as condições meteorológicas e de instabilidade da coluna d'água se tornam adversas ao desenvolvimento das cianobactérias, podendo levar à ocorrência de reduções bruscas e significativas em sua biomassa. A entrada de grandes volumes de água em pequenos intervalos de tempo combinada com a queda da temperatura do ar promove a desestratificação da coluna d'água e a dispersão da biomassa de cianobactérias, antes concentrada nas camadas superficiais, ao longo de toda a profundidade. Esse fenômeno ocorreu em dezembro de 2011, quando uma precipitação de 196 mm entre os dias 14 e 15 levou ao aumento do volume da lagoa de $11,25 \times 10^{6} \mathrm{~m}^{3}$ para $11,40 \times 10^{6} \mathrm{~m}^{3}$. Apesar do pequeno acréscimo no volume total da lagoa (cerca de 1,33\%), a biomassa foi reduzida em aproximadamente 30 vezes, de acordo com o modelo, entre os dias 14 (200 $\mu$ g chla. $\left.\mathrm{L}^{-1}\right)$ e 16 (7 $\mu \mathrm{g}$ chla. $\left.\mathrm{L}^{-1}\right)$ de dezembro. No mesmo período, a diferença entre a temperatura na superfície e no fundo da coluna d'água passou de 9,9 para $0,1^{\circ} \mathrm{C}$, indicando a desestratificação total da coluna d'água. O fenômeno da desestratificação seguido da diminuição da biomassa ocorreu de forma menos intensa em outros momentos ao longo do período de estudo, como, por exemplo, em abril de 2013.

Os efeitos de eventos chuvosos na dinâmica das cianobactérias são complexos e ainda pouco estudados (REICHWALDT \& GHADOUANI, 2012). Chuvas intensas podem diminuir a ocorrência de florações de cianobactérias devido à desestratificação e à turbulência da coluna d'água e ao aumento da turbidez (BOUVY et al., 2003; FIGUEREDO \& GIANI, 2001; 2009). Por outro lado, a desestratificação da coluna d'água pode ressuspender nutrientes que antes se encontravam retidos nos sedimentos e que passam a ficar biodisponíveis (PALMER-FELGATE et al., 2011). Um elevado número de chuvas de baixa intensidade pode favorecer os florescimentos algais devido à entrada de nutrientes (SHAW et al., 2001). No entanto, durante a ocorrência de chuvas mais intensas uma menor parcela de água infiltra no solo, gerando um maior volume de escoamento superficial cuja capacidade de carreamento de partículas, incluindo nutrientes, também é maior. Para o caso da Lagoa da Pampulha, não se delineia ainda com clareza um quadro regular de causas e efeitos, principalmente considerando-se o fato de tratar-se de um ambiente aquático tropical, onde todos os processos se desenvolvem em uma magnitude superior àquela encontrada em climas temperados.

O enfoque deste estudo consistiu na dinâmica do fitoplâncton, porém outras variáveis, como as concentrações em nitrato, amônia e fosfato, também foram modeladas. De modo geral, o modelo consegue fornecer boas ordens de grandeza para essas variáveis. Em relação à distribuição desses nutrientes na coluna d'água, observou-se que o nitrato se concentra na superfície, onde as concentrações em oxigênio são elevadas devido às trocas atmosféricas e à fotossíntese fitoplanctônica. O fosfato e a amônia estão presentes em maiores concentrações somente a partir de 2,0 m de profundidade, quando a concentração em oxigênio também decresce. Assim como ocorre para o fitoplâncton, a desestratificação da coluna d'água homogeneíza a distribuição vertical dos nutrientes, de modo que na superfície as concentrações em fosfato e amônia aumentam e a concentração em nitrato diminui.

\section{Mudanças na bacia hidrográfica e a dinâmica fitoplanctônica}

Na metodologia descrita neste artigo, o ambiente lacustre é tratado como uma peça que se integra e responde às modificações que ocorrem no seu entorno graças à integração do modelo hidrológico e do modelo da lagoa. Uma vez que ambos os modelos apresentaram bons resultados nas fases de calibração e validação e podem ser considerados aptos a reproduzir a dinâmica do fitoplâncton na Lagoa da Pampulha, torna-se possível utilizá-los para a simulação de cenários futuros.

Alterações no regime de chuva, na velocidade do vento e na temperatura do ar decorrentes de possíveis mudanças climáticas (HUNTINGTON, 2006) podem ser incorporadas aos dados de entrada do modelo hidrológico e do modelo da lagoa. Dessa forma, é possível avaliar como mudanças na estabilidade da coluna d'água e nas vazões produzidas na bacia podem se refletir sobre a dinâmica fitoplanctônica (MOOIJ et al., 2007; PAERL \& HUISMAN, 2008).

Da mesma forma, cenários envolvendo mudanças no uso do solo e impermeabilização de superfícies em decorrência da expansão da urbanização na bacia podem ser construídos com o objetivo de verificar as vazões máximas que chegam até a lagoa e seus impactos sobre o sistema lêntico. Nesse caso, os parâmetros "porcentagens impermeáveis" 
e "CN" devem ser alterados no modelo hidrológico de modo a corresponder aos cenários desejados.

\section{CONCLUSÕES E PERSPECTIVAS}

Neste estudo realizou-se a modelagem da dinâmica fitoplanctônica na Lagoa da Pampulha em conjunto com a modelagem do escoamento superficial nas duas maiores sub-bacias que compõem a bacia hidrográfica desse corpo d'água. Ambos os modelos foram calibrados e validados com dados obtidos em campo, o que assegura uma maior confiabilidade em seus resultados e em suas potenciais capacidades de extrapolação.

O modelo hidrológico reproduziu com sucesso as vazões escoadas nas bacias, as quais foram introduzidas como dado de entrada ao modelo da lagoa. O monitoramento e a modelagem da lagoa mostraram que a proliferação fitoplanctônica é bastante perturbada pelas desestratificações térmicas que ocorrem na lagoa em virtude de eventos meteorológicos. Em médio e longo prazo, a estratégia de gestão da lagoa deveria incluir metas de redução nas contribuições de fósforo, uma vez que a comunidade fitoplanctônica pode ter seu desenvolvimento limitado pela disponibilidade desse nutriente.

A integração entre os dois modelos realizada neste trabalho englobou apenas os aspectos quantitativos do escoamento superficial. A abordagem qualitativa pode também ser incluída acrescentando-se o módulo de simulação da qualidade da água no modelo hidrológico. Dessa forma, seria possível avaliar o efeito da poluição difusa sobre o corpo d'água receptor. Os cenários propostos para representar mudanças em decorrência da urbanização poderiam, assim, avaliar alterações na geração de poluentes dentro da bacia de drenagem.

O modelo hidrológico integrado ao modelo da lagoa possui potencial para estimar futuros impactos de uma provável expansão da urbanização sobre um corpo d'água que fornece importantes serviços ecossistêmicos (biodiversidade, lazer, paisagem, etc.) para Belo Horizonte. A ferramenta resultante da metodologia aqui descrita pode ser aplicada em outros lagos e reservatórios, desde que seja realizado o monitoramento necessário à calibração e à validação dos modelos.

\section{REFERÊNCIAS}

AFSSET - Agence Française de Sécurité Sanitaire de L'environnement et du Travail. (2006) Risques sanitaires liés à la présence de cyanobactéries dans l'eau. France: Rapport commun de l'Agence Française de Sécurité Sanitaire des Aliments et de l'Agence Française de Sécurité Sanitaire de l'environnement et du travail, 227p.

ALBERTI, M.; BOOTH, D.; HILL, K.; COBURN, B.; AVOLIO, C.; COES, S; SPIRANDELLI, D. (2007) The impact of urban patterns on aquatic ecosystems: an empirical analysis in Puget lowland sub-basins. Landscape and Urban Planning, v.80, n.4, p.345-361.

ANDERSON, T.R. (2005) Plankton functional type modelling: running before we can walk? Journal of Plankton Research, v.27, n.11, p.1073-1081.

APHA - American Public Health Association. (1998) Standard methods for the examination of water and wastewater. $2 \mathrm{O}^{\text {th }}$ ed. Washington, EUA: American Public Health Association.

ARHONDITSIS, G.B. \& BRETT, M.T. (2004) Evaluation of the current state of mechanistic aquatic biogeochemical modelling. Marine Ecology Progress Series, v.271, p.13-26.

BENNIS, S. \& CROBEDDU, E. (2007) New Runoff Simulation Model for Small Urban Catchments. Journal of Hydrologic Engineering, v.12, n.5, p.540-544.

BERTRAND-KRAJEWSKI, J.L.; LAPLACE, D.; JOANNIS, C.; CHEBBO, G. (1997) Mesures en Hydrologieurbaine et assainissement. Paris: Editions Tec \& Doc. 793p.
BONNARY, M. (2011) Modélisation d'un bassin hydrologique : application au bassin de Pampulha (BeloHorizonte, Brésil). Relatório de estágio Paris: Ecole des Ponts Paris Tech. 86p.

BOUVY, M.; NASCIMENTO, S.M.; MOLICA, R.J.R.; FERREIRA, A; HUSZAR, V; AZEVEDO, S.M.F.O. (2003) Limnologicalfeatures in Tapacurareservoir (northeastBrazil) during a severedrought. Hydrobiologia, v.493, n.1-3, p.115-130

COOKE, G.D.; WELCH, E.B.; PETERSON, S.A.; NICHOLS, S.A. (2005) Restauration and Management of Lakes and Reservoirs. $3 a$ ed. Boca Raton, EUA: Taylor \& Francis Group. 575p.

CPRM - Serviço Geológico do Brasil. (2001) Estudo Hidrogeológico da Bacia da Lagoa da Pampulha. BEATO, D.A.C. (Ed.). Belo Horizonte: CPRM. 151p.

DOTTO, C.B.S.; MANNIMA, G.; KLEIDORFER, M.; VEZZARO, L.; HENRICHS, M.; MCCARTHY, D.T.; FRENI, G.; RAUCH, W.; DELETIC, A. (2O12) Comparison of different uncertainty techniques in urban storm water quantity and quality modelling. WaterResearch, v.46, p.2545-2558.

FIGUEREDO, C.C. \& GIANI, A. (2001) Seasonal variation in the diversity and species richness of phytoplankton in a tropical eutrophic reservoir Hydrobiologia, v.445, p.165-174

FIGUEREDO, C.C. \& GIANI, A. (2009) Phytoplankton community in the tropical lake of Lagoa Santa (Brazil): Conditions favouring a persistent bloom of Cylindrospermopsisraciborskii. Limnologica - Ecology and Management of Inland Waters, v.39, p.264-272. 
FRAGOSO JUNIOR, C.R. (2007) Modelagem tridimensional da estrutura trófica em ecossistemas aquáticos continentais rasos. Tese (Doutorado) - Instituto de Pesquisas Hidraúlicas, 200 p.

GAL, G.; HIPSEY, M. R.; PARPAROV, A.; WAGNER, U.; MAKLER, V.; ZOHARY, T. (2009) Implementation of ecological modelling as an effective management and investigation tool: Lake Kinneret as a case study. Ecological Modelling, v.220, p.1697-1718.

HAMILTON, D.P. \& SCHLADOW, S.G. (1997) Prediction of water quality in lakes and reservoirs. Part I - Model description. Ecological Modelling, v.96, n.1-3, p.91-110.

HIPSEY, M.R.; ROMERO, J.R.; ANTENUCCI, J.P.; HAMILTON, D.P. (2OO6) Computational Aquatic Ecosystem Dynamics Model - CAEDYM Science Manual: Centre for Water Research, University of Western Australia, 102p.

HUNTINGTON, T.G. (2006) Evidence for intensification of the global water cycle: review and synthesis. Journal of Hydrology, v.319, n.1-4, p.83-95.

LOPES, A.M.M.B. (2013). Composição da comunidade de cianbactérias e outros grupos microbianos em dois reservatórios tropicais. Tese (Doutorado em Ecologia, Conservação e Manejo da Vida Silvestre) Universidade Federal de Minas Gerais, Belo Horizonte, 157p.

MOOIJ, W.M.; JANSE, J.H.; DOMIS, L.N.S.; HULSMANN, S.; IBELINGS, B.W. (2007) Predicting the effect of climate change on temperate shallow lakes with the ecosystem model PCLake. Hydrobiologia, v.584, p.443-454.

NASCIMENTO, N.O.; HELLER, L.; KNAUER, S.; BAPTISTA, M.; HELLER, P.; CHERNICHARO, C.; CHAMPS, J.R. (2006) Long-term uncertainties and potential risks to urban waters in Belo Horizonte. Belo Horizonte: SWITCH project, 38p.

NASH, J. \& SUTCLIFFE, J. (1970) River flow forecasting through conceptual models part I: discussion of principles. Journal of Hydrology, v.10, n.3, p.282-290.

NOBRE, A.M.; FERREIRA, J.G.; NUNES, J.P.; YAN, X.; BRICKER, S.; CORNER, R.; GROOM, S.; GU, H.; HAWKINS, A.J.S.; HUTSON, R.; LAN, D.; SILVA, J.D.L.; PASCOE, P.; TELFER, T.; ZHANG, X.; ZHU, M. (2O10) Assessment of coastal management options by means of multilayered ecosystem models. Estuarine, Coastal, and Shelf Science, p.1-20.

NORTON, L.; ELLIOT, J.A.; MARBELY, S.C.; MAY, L. (2012) Using models to bridge the gap between land use and algal blooms: an example from the Loweswater catchment, UK. Environmental Modelling and Software, v.36, p.64-75.

NUSCH, E.A. (1980) Comparison of different methods for chlorophyll and phaeopigment determination. Archives of Hydrobiology Beiheft Etgebn Limnology, v.14, p.14-36.

PADISÁK, J. (1997) Cylindrospermosisraciborskii (Woloszynska) SeenayyaetSubbaRaju, an expanding, highly adaptativecyanobacterium: worldwide distribution and review of its ecology. Archives of Hydrobiology, v.4, p.563-593.
PAERL, H.W. \& HUISMAN, J. (2008) Blooms Like It Hot. Science, v.32O, p.57-58.

PALMER-FELGATE, E.J.; MORTIMER, R.J.; KROM, M.D.; JARVIE, H.P.; WILLIAMS, R.J.; SPRAGGS, R.E.; STRATFORD, C.J. (2O11) Internal load of phosphorus in a sedimentation pond of a treatment wetland: effect of a phytoplankton crash. The Science of the Total Environment, v.409, n.11, p.2222-2232.

PETRUCCI, G. \& BONHOMME, C. (2014) The dilemma of spatial representation for urban hydrology semi-distributed modelling: tradeoffs among complexity, calibration and geographical data. Journal of Hydrology, v.517, p.997-1007.

PETRUCCI, G.; RIOUST, E.; DEROUBAIX, J-F.; TASSIN, B. (2O13) Do storm water source control policies deliver the right hydrologic outcomes? Hydrology of peri-urban catchments: processes and modelling, v.2, p.188-200

REICHWALDT, E.S. \& GHADOUANI, A. (2O12) Effects of rainfall patterns on toxic cyanobacterial blooms in a changing climate: between simplistic scenarios and complex dynamics. Water Research, v.46, p.1372-1393.

RESCK, R.P.; BEZERRA, N.J.F.; MOTA COELHO, R.M. (2007) Nova Batimetria a avaliação de parâmetros morfométricos da Lagoa da Pampulha (Belo Horizonte, Brasil). Geografias artigos científicos, v.3, n.2, p.24-37.

REYNOLDS, C.S. (2006) The Ecology of Phytoplankton. Cambridge: Cambridge University Press, 535p.

ROCHE, M. (1963) Hydrologie de surface. Paris: Gauthier-Villars Editeur, 390p.

ROSSMAN, L.A. (2010) Storm Water Management Model. User's Manual, version 5.O. U.S. EPA, Water Supply and Water Resources Division, National Risk Management Research Laboratory, Cincinnati (USA), 295p.

SCHEFFER, M.; RINALDI, S.; GRAGNANI, A.; MUR, L.R.; VAN NES, E.H. (1997) On the dominance if filamentous cyanobacteria in shallow, turbid lakes. Ecology, v.78, n.1, p.272-282.

SHAW, G.; GARNETT, C.; MOORE, M.R.; FLORIAN, P. (2001) The predicted impact of climate change on toxic algal (Cyanobacterial) blooms and toxin production in Queensland. Environmental Health, v.1.

SMITH, V.H. (2003) Eutrophication of freshwater and coastal marine ecosystems: a global problem. Environnement Science and Pollution Research, v.10, n.2, p.126-139.

TANER, M.Ü.; CARLETON, J.N.; WELLMAN, M. (2011) Integrated model projections of climate change impacts on a North American lake Ecological Modelling, v.222, p.3380- 3393.

TÔRRES, I.C.; RESCK, R.; PINTO-COELHO, R. (2007). Mass balance estimation of nitrogen, carbon, phosphorus and total suspended solids in the urban eutrophic, Pampulha reservoir, Brazil. Acta Limnologica Brasiliensia, v.19, p.79-91. 
TROLLE, D; JØRGENSEN, T.B; JEPPESEN, E. (2008) Predicting the effects of reduced external nitrogen loading on the nitrogen dynamics and ecological state of deep Lake Ravn, Denmark, using the DYRESM-CAEDYM model. Limnologica - Ecology and Management of Inland Waters, v.38, n.3-4, p.220-232.

TROLLE, D.; HAMILTON, D.P.; PILDITCH, C.A.; DUGGAN, I.C.; JEPPESEN, E. (2011). Predicting the effects of climate change on trophic status of three morphologically varying lakes: Implications for lake restoration and management Environmental Modelling \& Software, v.26, n.4, p.354-370.

TUCCI, C.E.M. (2005) Modelos Hidrológicos. 2a ed. Porto Alegre: UFRGS Editora; $\mathrm{ABRH}, 678 \mathrm{p}$

TUCCl, C.E.M. (2012) Hidrologia: ciência e aplicação. $4^{a}$ ed. Porto Alegre: UFRGS Editora e ABRH, 943p.

TVA - Tennessee Valley Authority. (1972) Heat and mass transfer between a water surface and the atmosphere. Tennessee, EUA: Tennessee Valley Authority, 174p.
UTERMÖHL, H. (1958) Zur Vervollkmnung der quantitativenPhytoplankton-Methodik. Internationale Vereinigung für Theoretische und Anwandte Limnologie, v.9, p.165-174.

WU, J.; YU, S.L.; ZOU, R.A (2006) Water Quality-Based Approach for Catchment Wide BMP Strategies. Journal of American Water Resources Association, v.42, p.1193-1204.

VIEIRA, P.C.; SEIDL, M.; NASCIMENTO, N.O.; SPERLING, M.V. (2009) Avaliação de fluxo de poluentes em tempo seco e durante eventos de chuva em uma microbacia urbanizada no município de Belo Horizonte. In: RIGHETTO, A.M. (Org.) Manejo de águas pluviais urbanas. Rio de Janeiro: ABES, p.346-366.

XU, Z.; GODREJ, A.N.; GRIZZARD, T.J. (2007) The hydrological calibration and validation of a complexly-linked catchment-reservoir model for the Occoquan catchment, Virginia. Journal of Hydrology v.345, p.167-183. 
Anexo I - Parâmetros de calibração dos modelos hidrológicos.

\begin{tabular}{|c|c|c|c|c|c|}
\hline \multicolumn{2}{|l|}{ Parâmetro } & \multirow{2}{*}{$\begin{array}{l}\text { Intervalo } \\
\text { de variação }\end{array}$} & \multirow{2}{*}{ Unidade } & \multicolumn{2}{|c|}{ Valor atribuído } \\
\hline Símbolo & Descrição & & & Ressaca & Sarandi \\
\hline $\mathrm{n}_{\text {cond }}$ & Coeficiente de rugosidade do canal & $0,011-0,14$ & - & 0,012 & 0,022 \\
\hline $\mathrm{d}_{\text {time }}$ & Tempo para secar um solo saturado & $0,5-7,0$ & dias & 6,84 & 0,560 \\
\hline $\mathrm{n}_{\mathrm{imp}}$ & Coeficiente de rugosidade de superfícies impermeáveis & $0,011-0,024$ & - & 0,011 & 0,011 \\
\hline $\mathrm{n}_{\text {perm }}$ & Coeficiente de rugosidade de superfícies permeáveis & $0,01-0,80$ & - & 0,012 & 0,054 \\
\hline $\mathrm{S}_{\mathrm{imp}}$ & Perdas iniciais em áreas impermeáveis & $0,4-2,54$ & $\mathrm{~mm}$ & 0,415 & 1,218 \\
\hline $\mathrm{S}_{\text {perm }}$ & Perdas iniciais em áreas permeáveis & $0,1-7,62$ & $\mathrm{~mm}$ & 0,168 & 2,820 \\
\hline$W_{\text {(médio) }}$ & Largura da bacia hidrográfica & 40-1500 & $\mathrm{m}$ & 840 & 1135 \\
\hline
\end{tabular}

Anexo II - Parâmetros de calibração do modelo da lagoa.

\begin{tabular}{|c|c|c|c|c|}
\hline Parâmetro & Símbolo & Unidade & Intervalo de variação & Valor atribuido \\
\hline \multicolumn{5}{|l|}{ Grupo fitoplanctônico: cianobactérias } \\
\hline Taxa de crescimento & $\mu_{\operatorname{maxc}}$ & $\mathrm{dia}^{-1}$ & $0,25-1,60$ & 1,60 \\
\hline Taxa de respiração & $\mathrm{k}_{\mathrm{RC}}$ & $\mathrm{dia}^{-1}$ & $0,05-0,15$ & 0,05 \\
\hline Fator temperatura para respiração & $\vartheta_{\mathrm{RC}}$ & - & $1,04-1,10$ & 1,05 \\
\hline Máxima concentração interna em P & AlP $_{\operatorname{maxc}}$ & mg P (mg Chla) $)^{-1}$ & $0,92-3,80$ & 2,84 \\
\hline Máxima absorção de P & $U P_{\operatorname{maxc}}$ & mg P (mg Chla) $)^{-1}$ dia-1 $^{-1}$ & $0,4-54,4$ & 24,4 \\
\hline Máxima absorção de N & $U N_{\operatorname{maxc}}$ & mg N (mg Chla) $)^{-1} \mathrm{dia}^{-1}$ & $0,2-4,8$ & 0,71 \\
\hline Temperatura ótima & $T_{\text {optc }}$ & ${ }^{\circ} \mathrm{C}$ & $25-35$ & 31 \\
\hline Coeficiente de atenuação & $\mathrm{k}_{\mathrm{e}}^{\mathrm{c}}$ & ugchla $\mathrm{L}^{-1} \mathrm{~m}^{-1}$ & $0,01-0,02$ & 0,017 \\
\hline Inclinação da curva P-I & $I_{\mathrm{kC}}$ & $\mu \mathrm{Em}^{-2} \mathrm{~s}^{-1}$ & $15-180$ & 70 \\
\hline
\end{tabular}

Grupo fitoplanctônico: outros

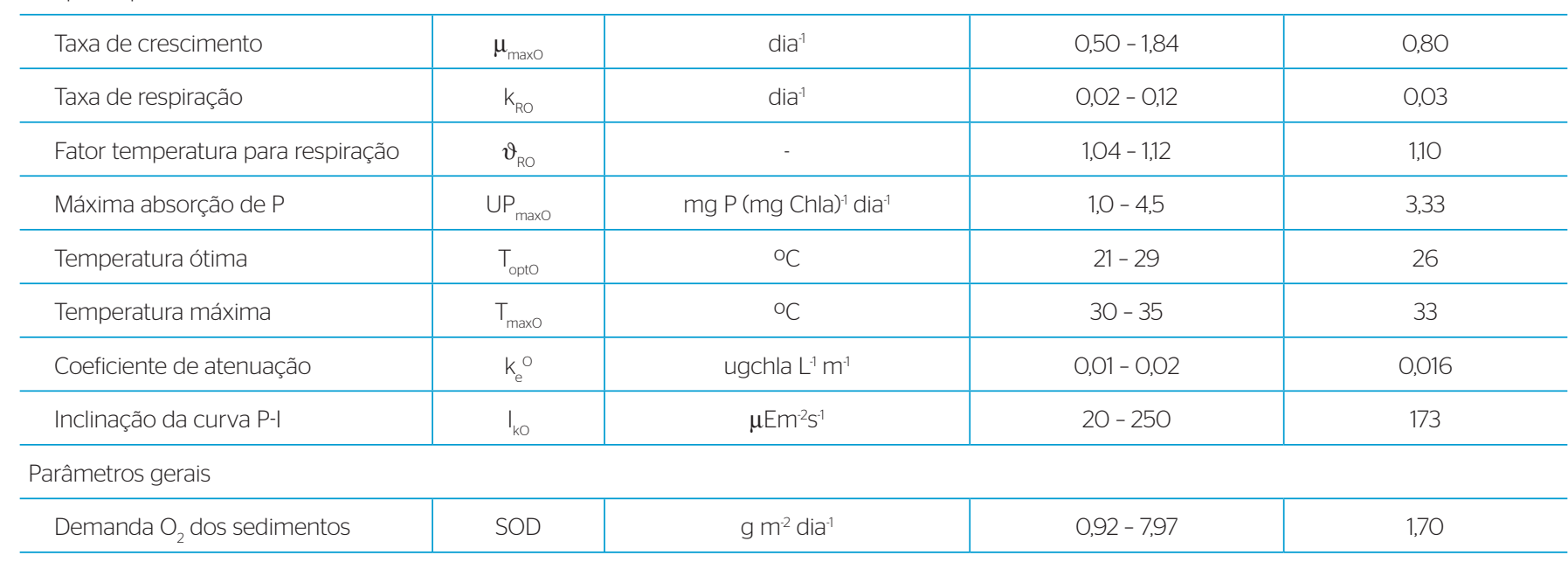

